\title{
TRANSIENT STABILITY ANALYSIS AND ENHANCEMENT OF IEEE- 9 BUS SYSTEM
}

\author{
Renuka Kamdar ${ }^{1}$, Manoj Kumar ${ }^{2}$ and Ganga Agnihotri ${ }^{3}$ \\ ${ }^{1,3}$ Department of Electrical Engineering, MANIT, Bhopal, India
}

\begin{abstract}
System stability study is the important parameter of economic, reliable and secure power system planning and operation. Power system studies are important during the planning and conceptual design stages of the project as well as during the operating life of the plant periodically. This paper presents the power system stability analysis for IEEE- 9 bus test system. The fault is created on different busses and transient stability is analyzedfor different load and generation conditions. The critical clearing time (CCT) is calculated by using time domain classical extended equal area criterion method. The system frequency and voltage variation is observed for different fault locations and CCT. The IEEE-9 bus test system is simulated and stability is analyzed on ETAP software.
\end{abstract}

\section{KEYWORDS}

Critical Clearing Time (CCT), ETAP, Extended Equal Area Criterion (EEAC), Frequency Stability, IEEE-9 Bus Test System, Load Flow Study, Load Shedding, Transient Stability.

\section{INTRODUCTION}

Electric power system stability analysis has been recognized as an important and challenging problem for secure system operation. When large disturbances occur in interconnected power system, the security of these power systems has to be examined. Power system security depends on detailed stability studies of system to check and ensure security.

In order to determine the stability status of the power system for each contingency of any disturbance occurs in power system, many stability studies are defined [1]. Power system stability analysis may involve the calculation of Critical Clearing time (CCT) for a given fault which is defined as the maximum allowable value of the clearing time for which the system remains to be stable. The power system shall remain stable if the fault is cleared within this time. However, if the fault is cleared after the CCT, the power system is most likely to become unstable. Thus, CCT estimation is an important task in the transient stability analysis for a given contingency. In this paper for the Transient Stability Analysis, an IEEE 9 Bus system is considered.

Critical clearing time (CCT) in a way measures the power systems Transient stability. It denotes the secure and safe time margin for clearing the contingency, usually three-phase ground-fault. The larger the value of CCT, the power system has ample time to clear the contingency. CCT depends on generator inertias, line impedances, grid topology, and power systems operating conditions, fault type and location. For a single machine infinite bus power system, CCT calculation is straightforward. While for the case of multi-machine power systems, CCT is always DOI : $10.14810 /$ ecij.2014.3204 
obtained by repeating time-domain simulations, and hence the evaluation of CCT can only be done off-line The Load Flow study and Transient Stability study is discussed and performed for the IEEE-9 Bus test system simulated on ETAP 7.5.1.

\section{POWER SYSTEM STABILITY}

Power system stability is defined as the capability of a system to maintain an operating equilibrium point after being subjected to a disturbance for given initial operating conditions [4]. Power system stability is categorized based on the following considerations:

i. The nature of the resulting instability mode indicated by the observed instability on certain system variables.

ii. The size of the disturbance which consequently influences the tool used to assess the system stability.

iii. The time margin needed to assess system stability.

The classification of power system stability as shown in Fig.1

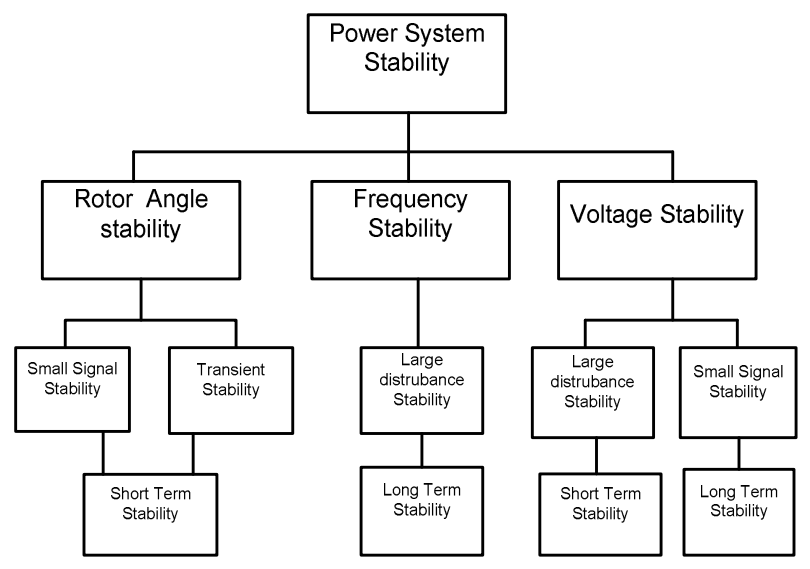

Fig. 1 Classification of Power System Stability

\section{SWING EQUATION}

The swing equation governs the motion of the machine rotor relating the inertia torque to the resultant of the mechanical and electrical torques on the rotor i.e.[5]

Where,

$$
M_{i} \frac{d^{2} \delta_{i}}{d t^{2}}=P_{m_{i}}-P_{e_{i}}, i=1,2,3, \ldots \ldots \ldots \ldots, n(1)
$$

$P_{e i}=\left|E_{i}\right|^{2} G_{i i}+\sum_{j=1}^{n}\left[\left|E_{i}\right|\left|E_{j}\right|\left|G_{i j}\right| \cos \left(\delta_{i}-\delta_{j}\right)+\left|E_{i}\right|\left|E_{j}\right|\left|B_{i j}\right| \sin \left(\delta_{i}-\delta_{j}\right)\right](2)$ 
With:

$\delta_{i}=$ rotor angle of the $\mathrm{i}$-th machine;

$M_{i}=$ inertia coefficient of the i-th machine;

$P_{m_{i}}, P_{e_{i}}=$ mechanical and electrical power of the $\mathrm{i}$-th machine;

$E_{i}=$ voltage behind the direct axis transient reactance;

$G_{i j}, B_{i j}=$ real and imaginary part of the $\mathrm{ij}$-th element of the nodal admittance matrix reduced at the nodes which are connected to generators

The following steps are taken for stability studies of multimachine system[6]:

1. From the pre-fault load flow data determined $E_{k}$ voltage behind transient reactance for all generators. This establishes generator emf magnitudes $\left|E_{k}\right|$ which remain constant during the study and initial rotor angle $\delta_{k}^{0}=$ angle $\left(E_{k}\right)$. Also record prime mover inputs to generators, $P_{m k}=P_{G K}^{0}$.

2. Augmented the load flow network by the generator transient reactance. Shift network buses behind the transient reactance.

3. Find $Y_{B U S}$ for various network conditions-during, post fault (faulted line cleared), after line reclosure.

4. For faulted mode, found generator outputs from power angle equation $P_{e i}=\left|E_{i}\right|^{2} G_{i i}+$ $\left|E_{i}\right|\left|E_{j}\right|\left|Y_{i j}\right| \cos \left(\delta_{i}-\delta_{j}-\theta_{i j}\right)$ and solve swing equations.

5. The above step is repeated for post fault mode and after line reclosure mode.

6. Examined $\delta(t)$ plots of all generators and established the answer to the stability question.

The following preliminary calculation steps are needed for transient stability analysis of multi-machine system[4]:

1. Prepare the system data generally at 100 MVA base.

2. Loads are represented by equivalent shunt admittances.

3. Calculate the generator inter voltages and their initial angles.

4. Calculate the admittance bus matrix $Y_{B U S}$ for each network condition.

5. Except for the internal generator nodes, eliminate all the nodes and obtain the $Y_{B U S}$ matrix for the reduced network. The reduced $Y_{B U S}$ matrix is obtained as shown below :

Let $I=Y V$

$$
\begin{gathered}
I=\left[\begin{array}{c}
I_{n} \\
0
\end{array}\right] \\
{\left[\begin{array}{c}
I_{n} \\
0
\end{array}\right]=\left[\begin{array}{ll}
Y_{n n} & Y_{n r} \\
Y_{r n} & Y_{r r}
\end{array}\right]\left[\begin{array}{l}
V_{n} \\
V_{r}
\end{array}\right]}
\end{gathered}
$$

Where $\mathrm{n}$ denotes generator nodes and $\mathrm{r}$ denotes remaining nodes.

$$
I_{n}=Y_{n n} V_{n}+Y_{n r}, \quad 0=Y_{r n} V_{n}+Y_{r r} V_{r}
$$

From which we eliminate $V_{r}$,

$$
I_{n}=\left(Y_{n n}-Y_{n r} Y_{r r}^{-1} Y_{r n}\right) V_{n}
$$


The matrix $\left(Y_{n n}-Y_{n r} Y_{r r}{ }^{-1} Y_{r n}\right)$ is the desired reduced $Y_{B U S}$ matrix. It is $(n \times n)$ matrix where $n$ is the number of generators.

When large disturbances occur in power system, there is no availability of generalized criteriafor determining system stability. Hence the experimental approach for the solution of transient stability problem is all about listing of all important severe disturbances along with their possible locations to which the system is likely to be subjected.

A plot of power angle $\delta$ and t (time) is called the swing curve which is obtained by numerical solution of the swing equation in the presence of large severe disturbances. If $\delta$ starts to decrease after reaching a maximum value, it is normally assumed that the system is stable and the oscillation of $\delta$ around the equilibriumpoint will decay and finally die out. Important severedisturbances are a short circuit fault or a sudden loss of load [3].

\section{CRITICAL CLEARING TIME CALCULATION USING EEAC}

Since the time EEAC was proposed in literature, a great interest has been raised on it [7-11], because it is able to yield fast and accurate transient stability analysis. In order to determine the stability of the power system as a response to a certain disturbance, the extended equal area criterion (EEAC) method described in [10] decomposes the multi-machine system into a set of critical machine(s) and a set of the 'remaining' generators. In order to form an OMIB system, the machines in the two groups are aggregated and then transformed into two equivalent machines. Some basic assumptions for EEAC are : (i) The disturbed system separation depends upon the angular deviation $\mathrm{b} / \mathrm{w}$ the following two equivalent clusters: the critical machine group $(\mathrm{cmg})$ and the remaining machine group(rmg), (ii) The partial centre of angles (PCOA) of the critical machine group $\left(\delta_{c m g}\right)$ and The partial centre of angles (PCOA) of the remaining machine $\operatorname{group}\left(\delta_{r m g}\right)$ :

$$
\begin{array}{r}
\delta_{c m g}=\frac{\sum_{i \epsilon c m g} M_{i} \delta_{i}}{M_{c m g}} \\
M_{c m g}=\sum_{i \epsilon c m g} M_{i}(4) \\
\delta_{r m g}=\frac{\sum_{j \epsilon r m g} M_{j} \delta_{j}}{M_{r m g}}(5) \\
M_{r m g}=\sum_{j \epsilon r m g} M_{j}(6)
\end{array}
$$

On the basis of above assumption, a multi-machine system can be transformed into equivalent two-machine system. After which, the two machine equivalent is reduced to a single machine infinite bus system. The equivalent One-machine-Infinite-Bus (OMIB) system model is given by the following equation:

$$
M \frac{d^{2} \delta}{d t^{2}}=P_{m}-P_{e}=P_{m}-\left[P_{c}+P_{\max } \sin (\delta-\gamma)\right]
$$


Where,

$$
\begin{gathered}
M=\frac{M_{c m g} M_{r m g}}{M_{T}} \\
M_{T}=\sum_{i=1}^{n} M_{i} \\
\delta=\delta_{c m g}-\delta_{r m g} \\
P_{c}=\frac{M_{r m g} \sum_{i, k \epsilon c m g} E_{i} E_{k} G_{i k}-M_{c m g} \sum_{j, l \epsilon r m g} E_{j} E_{l} G_{j l}}{M_{T}} \\
P_{m}=\frac{M_{r m g} \sum_{i \epsilon c m g} P_{m i}-M_{c m g} \sum_{j \epsilon r m g} P_{m j}}{M_{T}} \\
P_{m a x}=\sqrt{C}^{2}+D^{2} \\
\gamma=\frac{M_{r m g}-M_{c m g}}{M_{T}} \sum_{i \epsilon c m g, j \epsilon r m g} E_{i} E_{j} G_{i j} \\
D=\frac{M_{r m g}-M_{c m g}}{M_{T}} \sum_{i \epsilon c m g, j \in r m g} E_{i} E_{j} B_{i j}
\end{gathered}
$$

The accelerating and decelerating areas are given by [12]:

$$
\begin{aligned}
& A_{a c c}=\left(P_{m}-P_{c D}\right)\left(\delta_{c r}-\delta_{0}\right)+P_{\max D}\left[\cos \left(\delta_{c r}-\gamma_{D}\right)-\cos \left(\delta_{0}-\gamma_{D}\right)\right] \\
& A_{d e c}=\left(P_{c P}-P_{m}\right)\left(\pi-\delta_{c r}-\delta_{P}+2 \gamma_{P}\right)+P_{\max P}\left[\cos \left(\delta_{c r}-\gamma_{P}\right)+\cos \left(\delta_{P}-\gamma_{P}\right)\right](9)
\end{aligned}
$$

Where 0 denotes original (pre-fault), D during fault, and P post-fault, $\delta_{c r}$ is the critical clearing time.

The transient stability margin: $\mu=A_{a c c}-A_{d e c}$, at the critical clearing time $t_{c r}, \mu=A_{a c c}-$ $A_{\text {dec }}=0$

Solving the equations (13) \& (14), the critical clearing angle $\delta_{c r}$ can be computed. The value of critical clearing time (CCT) can be computed [17] by following formula:

$t_{c r}=\sqrt{\frac{2 M}{\omega_{0} P_{o}}\left(\delta_{c r}-\delta_{0}\right)}$

Where,

$P_{o}=$ generator output before fault

$\delta_{0}=$ pre-fault angle 


\section{SYSTEM SIMULATION AND LOAD FLOW ANALYSIS}

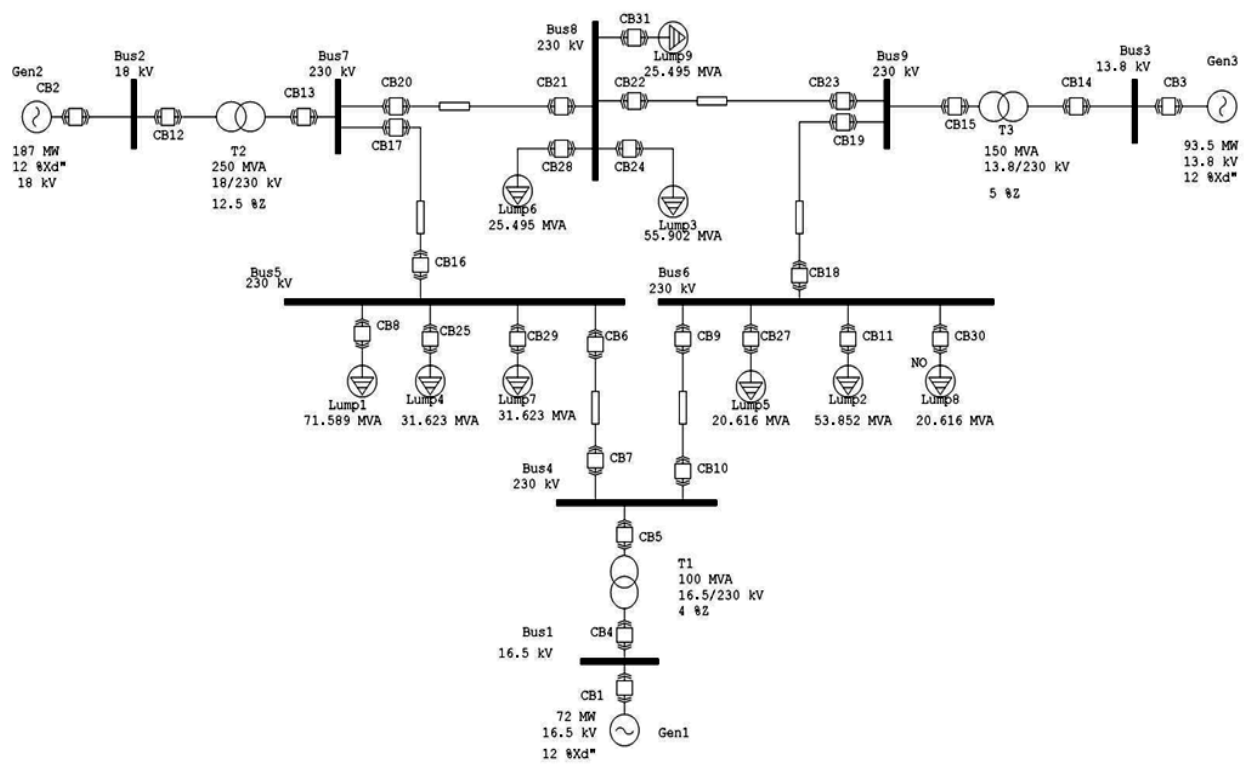

In this paper IEEE 9 bus system is used as the test system, which is simulated on ETAP 7.5.1.

Fig. 2 Single Line Diagram of IEEE 9 Bus test system

The single line diagram (SLD) of the simulated test system on ETAP is shown in Fig 2. For this test system generator and load parameters are given in appendix. The total generation is $313 \mathrm{MW}$ and total load is $312.5 \mathrm{MW}$. The test system contains 6 lines connecting the bus bars in the system with the generator connected to network through step-up transformer at $230 \mathrm{kV}$ transmission voltage.

It is good practice to have periodic and updated load flow study for every installation. The purpose of load flow study is

i. To calculate bus voltage levels tocompare to equipment ratings anddistribution system operatingrequirements

ii. To calculate branch current flows for comparing it to equipment ampacity ratings and protective device triplevels.

Depending upon the type of plant there can be many load flow cases to study. The objective is to identify the best and worst operating conditions. Several load flow solution algorithms used in industry such as Gauss-Seidel, Newton-Raphson and current injection. There is requirement of at least one swing bus in the network for all the Load flow solution algorithms. The utility point of service is always modeled as swing bus.

The result of load flow analysis when all generators and loads are operating at rated power is given in Table.1. Calculation of critical clearing time (CCT) by using EEAC for different generation and loading condition at the different fault locations are shown in Table. 2. 
This CCT is then used to operate the circuit breakers near the faulted bus and hence the corresponding generators are removed from the system. This creates the generation - load imbalance and hence the system frequency is affected.

When the frequency of the system crosses the permissible limit after the fault has occurred, the frequency protection scheme is activated. The frequency stability of the system is enhanced using Load Shedding.

Table.1 Load Flow Report

\begin{tabular}{|c|c|c|c|c|c|c|c|}
\hline $\begin{array}{c}\text { Bus } \\
\text { No. }\end{array}$ & $\begin{array}{c}\text { Bus } \\
\text { KV }\end{array}$ & $\begin{array}{c}\text { Voltage } \\
\text { Mag. } \%\end{array}$ & $\begin{array}{c}\text { Voltage } \\
\text { Angle }\end{array}$ & $\begin{array}{c}\text { Gen. } \\
(\mathrm{MW})\end{array}$ & $\begin{array}{c}\text { Gen. } \\
\text { (Mvar) }\end{array}$ & $\begin{array}{c}\text { Load } \\
(\mathrm{MW})\end{array}$ & $\begin{array}{c}\text { Load } \\
\text { (Mvar) }\end{array}$ \\
\hline 1 & 16.5 & 100.0 & 1.0 & 73.831 & 9.738 & 0 & 0 \\
\hline 2 & 18.0 & 100.0 & 0.3 & 155.00 & 92.091 & 0 & 0 \\
\hline 3 & 13.8 & 100.0 & -0.2 & 85.00 & 41.951 & 0 & 0 \\
\hline 4 & 230 & 98.940 & -4.3 & 0 & 0 & 0 & 0 \\
\hline 5 & 230 & 98.827 & -4.3 & 0 & 0 & 123.947 & 49.550 \\
\hline 6 & 230 & 98.834 & -4.3 & 0 & 0 & 89.247 & 29.726 \\
\hline 7 & 230 & 99.132 & -4.3 & 0 & 0 & 0 & 0 \\
\hline 8 & 230 & 98.884 & -4.3 & 0 & 0 & 99.284 & 34.790 \\
\hline 9 & 230 & 99.005 & -4.3 & 0 & 0 & 0 & 0 \\
\hline
\end{tabular}

Table.2CCT for different generation - loading conditions

\begin{tabular}{|c|c|c|}
\hline Cases & Fault Bus & CCT(sec) \\
\hline 1 & Bus 1 & 0.361109 \\
\hline 2 & Bus 2 & 0.31693 \\
\hline 3 & Bus 3 & 0.317587 \\
\hline
\end{tabular}

For the above mentioned generation - loading conditions, load shedding was performed till the system frequency stability is regained. The bus frequency and bus voltage plots for the three cases are shown in Fig. 3- Fig 8.

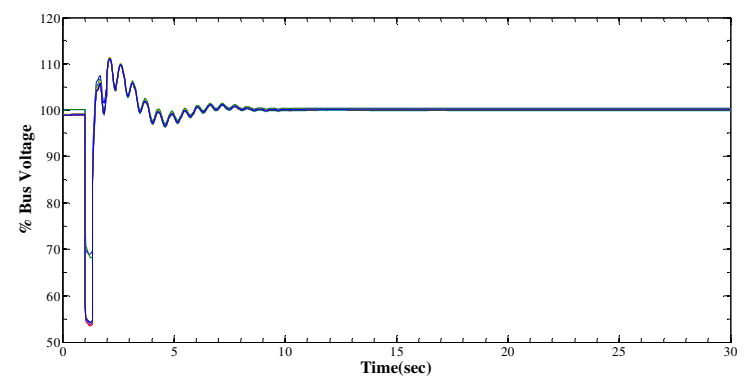

Fig.3 Bus voltage when the fault has occurred at bus 1

At $\mathrm{t}=1.0 \mathrm{sec} 3$ phase faultoccurred at bus 1 , the circuit breaker 1 and 4 are operated before the CCT calculated for the case i.e. at $1.36 \mathrm{sec}$. As a result generator 1 is removed from the system 
and the power imbalance condition arises. Due to this the load shedding scheme is activated and an amount of $68 \mathrm{MW}$ load is curtailed to regain the system stability. Similarly when the fault occurs at bus 2 and 3 leading to generator 2 and 3 outage respectively, the load of $150 \mathrm{MW}$ and 84 MW is shed from the system.

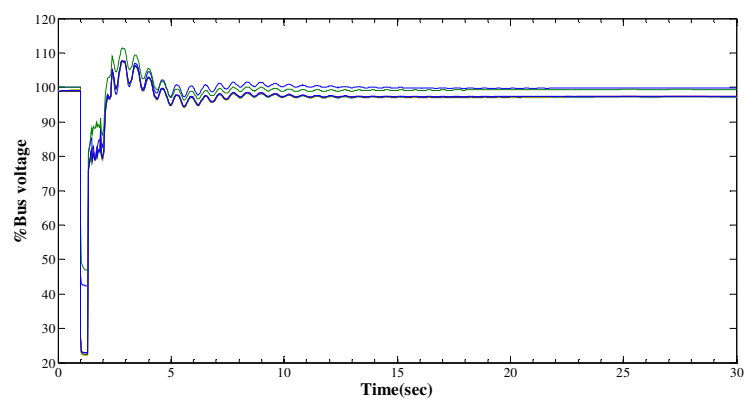

Fig.4 Bus voltage when the fault has occurred at bus 2

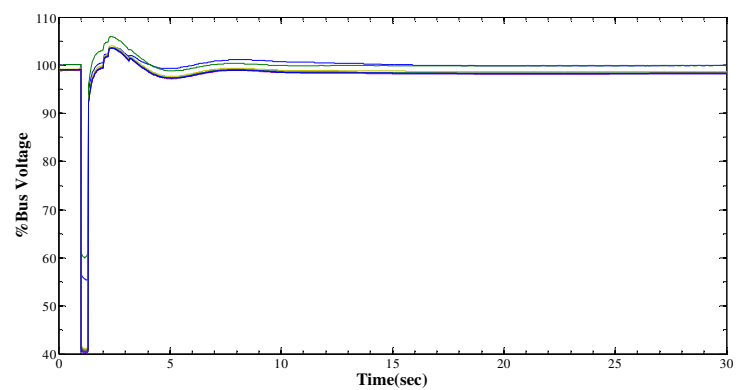

Fig.5 Bus voltage when the fault has occurred at bus 2

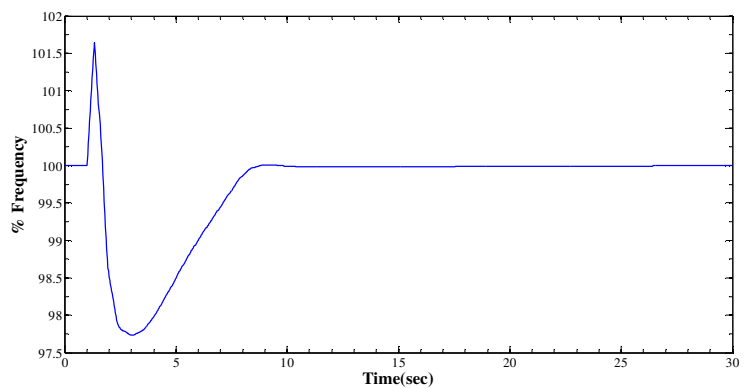

Fig.6 Bus frequencyafter load shedding when fault has occurred at bus1 
Electrical \& Computer Engineering: An International Journal (ECIJ) Volume 3, Number 2, June 2014

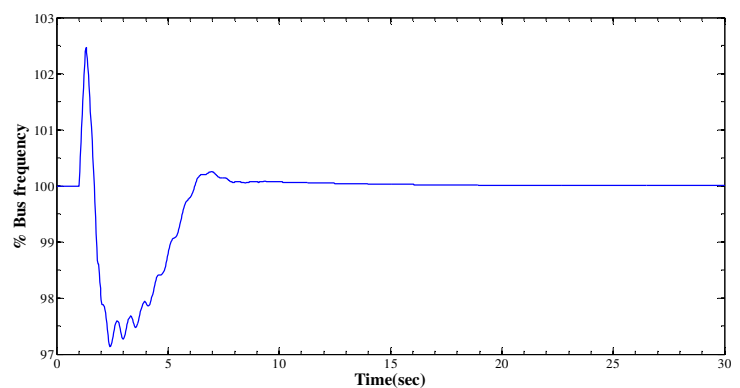

Fig.7 Bus frequency after load shedding when fault has occurred at bus2

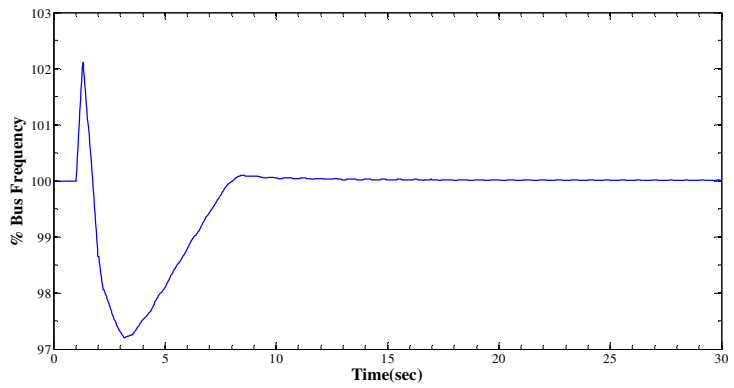

Fig.8 Bus frequency after load shedding when fault has occurred at bus3

\section{CONCLUSION}

Transient stability analysis has been performed on ETAP software. The Critical Clearing time (CCT) i.e. the maximum allowable value of the clearing time for which the system remains to be stable is calculated for a given fault. System frequency and voltage is analyzed for different loading conditions and faults on busses. The excess amount of load has to be shedded to maintain system stability.

\section{APPENDEX}

Generator data of IEEE 9 bus system

\begin{tabular}{|c|c|c|c|}
\hline Parameter & G1 & G2 & G3 \\
\hline Operation mode & Swing & Voltage control & $\begin{array}{c}\text { Voltage } \\
\text { control }\end{array}$ \\
\hline Rated MVA & 80 & 220 & 110 \\
\hline KV & 16.5 & 18 & 13.8 \\
\hline Power factor & 0.90 & 0.85 & 0.85 \\
\hline Type & Hydro & Thermal & Thermal \\
\hline Speed & 1500 & 1500 & 1500 \\
\hline$T_{d o}^{\prime}$ & 5.6 & 5.6 & 5.6 \\
\hline$T_{q o}^{\prime}$ & 3.7 & 3.7 & 3.7 \\
\hline
\end{tabular}


Load data of IEEE 9 bus system

\begin{tabular}{|c|c|c|}
\hline Load id & $\begin{array}{c}\text { Rating } \\
\text { (MVA) }\end{array}$ & Rated KV \\
\hline Lump1 & 71.589 & 230 \\
\hline Lump2 & 53.852 & 230 \\
\hline Lump3 & 55.902 & 230 \\
\hline Lump4 & 31.623 & 230 \\
\hline Lump5 & 20.616 & 230 \\
\hline Lump6 & 25.495 & 230 \\
\hline Lump7 & 31.623 & 230 \\
\hline Lump8 & 20.616 & 230 \\
\hline Lump9 & 25.495 & 230 \\
\hline
\end{tabular}

\section{REFERENCES}

[1] Mihirig, A.M., Wvong, M. D., "Transient stability analysis of multi-machine power systems by catastrophe theory," Generation, Transmission and Distribution, IEE Proceedings C, vol.136, no.4, pp.254-258, Jul 1989.

[2] P. Kundur, Power System Stability and Control, New York: McGraw-Hill, 1994 pp 104-120.

[3] Thomas P. Smith, "Power System Studies for Cement Plants", IEEE Industry Applications Magazine, pp. 56-65 July-Aug 2007

[4] IEEE/CIGRE Joint Task Force on Stability Terms and Definitions, "Definitions and Classification of Power System Stability,” IEEE Trans. on Power Systems, vol. 19, no. 3, August 2004, pp. 1387-1401

[5] Anderson, P. M., and Fouad, A. A., "Power System Control and Stability", New York: Wiley Interscience, 2002. pp. 34 -56.

[6] D. P. Kothari, I. J. Nagrath, "Modern Power System Analysis",India: Tata McGraw-Hill Publishing Company Limited, 2003. pp.433-510.

[7] Xue Y., VanCutsem T., Ribbens-Pavella, M., "Extended Equal Area Criterion, Justifications, Generalization, Applications”, IEEE Trans. on Power Systems, 1989, vol.4, no.1, pp.4452

[8] Xue Y., Wehenkel L., Pavella M., et al: Extended Equal Area Criterion Revisited, IEEE Trans. PowerSystems, 1992, vol.7, no.3, pp.1012-1022

[9] Xue Y., PavellaM.:Critical Cluster Identification in Transient Stability Studies, IEE Proc. Pt. C, 1993, vol.140, pp. 481-480

[10] Xue Y., Rousseax P, Gao Z, Wehenkel L., Pavella M., Belhomme M., Euxibie E., Heilbronn B.: Dynamic Extended Equal Area Criterion. Part 1: Basic Formulation, Athens Power Technol., 1993

[11] Y. Xue and M. Pavella, "Extended equal-area criterion: an analytical ultra-fast method for transient stability assessment and preventive control of power systems," International Journal of Electrical Power \& Energy Systems, vol. 11, no. 2, pp. 131-149, Apr. 1989.

[12] Pai, M. A., "Energy function analysis for power system stability", Kluwer Academic Publishers Boston/London, 1931

[13] Ibrahim M. El-Amin, Abdul-Aziz M. Al-Shames, “Transient stability assessment using artificial neural networks" Electric Power System Research,1997, pp. 7-16

[14] Kato, Y., Iwamoto, S., "Transient stability preventive control for stable operating condition with desired CCT," Power Engineering Society General Meeting, 2003, IEEE, vol.3, no., pp. 4 vol. 2666, 13-17 July 2003 doi: 10.1109/PES.2003.1267434

[15] Dong, Y., Pota, H.R., "Transient stability margin prediction using equal-area criterion ," Generation, Transmission and Distribution, IEE Proceedings C, vol.140, no.2, pp.96-104, Mar 1993 
[16] Krishna, D.R., Murthy, K., Rao, G.G., "Application of Artificial Neural Networks in Determining Critical Clearing Time in Transient Stability Studies," Power System Technology and IEEE Power India Conference, 2008, POWERCON 2008, Joint International Conference on , vol., no., pp.1-6, 1215 Oct. 2008

\section{Authors}

Renuka Kamdar was born in Bhopal, India in 1987. She has received her BE degree (Electrical and Electronics Engineering) from Oriental Institute of Science and Technology, Bhopal in 2009 and M. Tech degree (Power System) from MANIT Bhopal in 2013. She is presently working as a JRF in MANIT, Bhopal

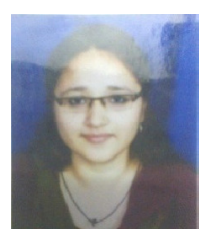

Dr. Ganga Agnihotri (M92118974) received BE degree in Electrical engineering from MACT, Bhopal (1972), the ME degree (1974) and PhD degree (1989) from University of Roorkee, India. Since 1976 she is with Maulana Azad College of Technology, Bhopal in various positions. Currently she is Professor. Her research interest includes Power System Analysis, Power System Optimization and Distribution Operation.

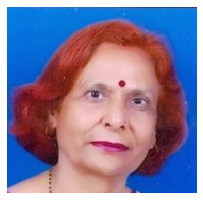

